\title{
Evaluation of modelling strategies for estimating cumulative damage on Groningen masonry buildings due to recursive induced earthquakes
}

\author{
Vasilis Sarhosis $^{1} \cdot$ Dimitris Dais $^{1,2} \cdot$ Eleni Smyrou $^{2} \cdot$ İhsan Engin Bal ${ }^{2}$ D
}

Received: 8 July 2018 / Accepted: 20 December 2018

(c) Springer Nature B.V. 2019

\begin{abstract}
The majority of houses in the Groningen gas field region, the largest in Europe, consist of unreinforced masonry material. Because of their particular characteristics (cavity walls of different material, large openings, limited bearing walls in one direction, etc.) these houses are exceptionally vulnerable to shallow induced earthquakes, frequently occurring in the region during the last decade. Raised by the damage incurred in the Groningen buildings due to induced earthquakes, the question whether the small and sometimes invisible plastic deformations prior to a major earthquake affect the overall final response becomes of high importance as its answer is associated with legal liability and consequences due to the damage-claim procedures employed in the region. This paper presents, for the first time, evidence of cumulative damage from available experimental and numerical data reported in the literature. Furthermore, the available modelling tools are scrutinized in terms of their pros and cons in modelling cumulative damage in masonry. Results of full-scale shaketable tests, cyclic wall tests, complex 3D nonlinear time-history analyses, single degree of freedom (SDOF) analyses and finally wall element analyses under periodic dynamic loading have been used for better explaining the phenomenon. It was concluded that a user intervention is needed for most of the SDOF modelling tools if cumulative damage is to be modelled. Furthermore, the results of the cumulative damage in SDOF models are sensitive to the degradation parameters, which require calibration against experimental data. The overall results of numerical models, such as SDOF residual displacement or floor lateral displacements, may be misleading in understanding the damage accumulation. On the other hand, detailed discrete-element modelling is found to be computationally expensive but more consistent in terms of providing insights in real damage accumulation.
\end{abstract}

Keywords Masonry $\cdot$ Cumulative damage $\cdot$ Induced seismicity $\cdot$ Discrete element method

İhsan Engin Bal

i.e.bal@pl.hanze.nl

1 School of Engineering, Newcastle University, Newcastle upon Tyne NE1 7RU, UK

2 Research Centre for Built Environment NoorderRuimte, Hanze University of Applied Sciences, Zernikeplein 11, Groningen, The Netherlands 


\section{Introduction}

Masonry is a brittle material with low strength threshold before presenting actual plastic deformations. This fact raises the question whether the small and sometimes invisible plastic deformations prior to a major earthquake play a significant role in the overall final response of masonry structures or not. This question has become an important issue especially in induced seismicity areas, such as Groningen (Netherlands), where several shallow, very small-magnitude earthquakes occur and affect the mostly-masonry-composed structural inventory before a relatively larger earthquake hits. In case of a significant earthquake, a damage claim mechanism is activated, rendering the question of possible previous damage prior to the main earthquake critical. It should be noted that the term "plastic deformation" here refers to masonry as a composition (as in Vasconcelos and Lourenço 2009; Zucchini and Lourenço 2009) rather than to the behaviour of the individual materials, such as the mortar or brick units.

This paper aims to find traces of cumulative damage from the available, though limited, experimental and numerical evidence in the literature. Also, available modelling tools are scrutinized in terms of their ability to model cumulative damage in masonry. Results of full-scale shake-table tests, cyclic wall tests, complex 3D nonlinear time-history analyses, SDOF analyses and finally discrete element analyses models of masonry wall panels, with and without openings, subjected to periodic dynamic loading were employed to better explain the phenomenon. The limitations of the available tools are also presented.

Structural materials subjected to repeated cyclic loading present weakening, an issue known as fatigue (readers are referred to Schijve 2009, for an introduction to the fatigue issue in general). Some of the available research treats the effect of cumulative loading on masonry from the fatigue point of view. For example, in Max et al. (2017) a rainflow algorithm is applied to experimental and numerical results of masonry specimens, in an effort to quantify non-structural damages in unreinforced masonry walls due to induced earthquakes in Basel and in St. Gallen, Switzerland. In cases where the load amplitudes are relatively high (still below the design values) but the number of cycles is low (typically lower than a few hundred thousand), the phenomenon is called low-cycle fatigue. There is an immense number of elastic cycles in high-cycle fatigue, while both elastic and small plastic deformations can be observed in much lower number of cycles in low-cycle fatigue. Past earthquakes with limited plastic deformations, in combination with pre-earthquake static loads and support settlements, are structural effects that resemble low-cycle fatigue in masonry (Elnashai and Di Sarno 2008; see also Chai 2005 for a discussion on the lowcycle fatigue and its effects on structures).

In order to study the effect of repeated seismic loads on structures, Hatzigeorgiou and Beskos (2009) conducted an extensive number of analyses on SDOF systems that resemble a variety of structural typologies and presented a simple approach for representing the inelastic displacement ratio of structures under recursive earthquakes. They found that repeated earthquakes have a significant effect on the inelastic displacement ratio and hence on the maximum inelastic displacement of the SDOF systems. In a similar but comparatively much more limited study, Aschheim and Black (1999) performed nonlinear analyses on SDOF systems where Takeda hysteresis model (Takeda et al. 1970) was used, without being able to identify a strong effect of previous earthquakes in these analyses, a result attributed to the nature of such hysteresis models, as explained further in their paper.

Di Sarno (2013) examines the case of multiple earthquakes occurring in a short period of time, and the effect of such phenomena on the seismic response of structures. For the 
case study analysed, it was shown that the seismic force demands on a structure can be thrice as compared to a single event, especially for structural periods above $1.0 \mathrm{~s}$. He further observed that multiple earthquakes warrant extensive and urgent studies, giving indications of the levels of lack of conservatism in the safety of conventionally-designed structures when subjected to multiple earthquakes.

Mouyiannou et al. (2014), on the other hand, studied the cumulative damage on masonry from repeated shocks, such as seismic sequence or multiple events and aftershocks affecting an unrepaired structure. They proposed an approach in which derivation of state-dependent fragility curves is possible, considering cumulated seismic damage, whilst neglecting possible ageing effects. Their approach is based on running cyclic analysis by imposing displacements up to the existing state of the structure and running the nonlinear time-histories after that state. After running SDOF models with real earthquake sequences from Christchurch in 2010 and 2011, they concluded that running fragility models only based on the main shock is inappropriate, since it provides missing information regarding the actual response of the structure.

Iervolino et al. (2013) approached the matter from a reliability perspective, introducing the gamma process, often used for finding the remaining life cycle of reliable systems. They illustrate, via a set of compatible equations and case-study applications, that the gamma process can be used to find the remaining strength and life time of structures after recursive earthquakes take place.

Chai (2005) proposed a low-cycle fatigue model into duration-dependent inelastic design spectra in order to allow for the effect of longer or repetitive earthquakes in the design process. His approach was based on the premise that, in order to ensure satisfactory performance of a structure, the cyclic plastic strain energy capacity of the structure must be larger than or equal to the portion of seismic input energy contributing to cumulative damage.

In this paper first, the findings of cumulative damage in full-scale shake-table experiments are discussed. Furthermore, results from quasi-static cyclic wall tests were employed to better explain the response of masonry walls under small cycles and in particular the accumulation of damage. In addition to the use of previously published experimental results, complex 3D time-history analysis results of typical Groningen houses were also evaluated for determining whether such analyses can shed light on the problem or not. Representative SDOF systems, calibrated to fit the seismic response of Groningen houses, have been used to parametrically define the accumulation of damage in terms of residual displacements. Finally, a series of discrete-element models, representative of masonry wall panels with and without openings were developed and subjected to periodic recursive loads with varying amplitudes and frequency in order to understand the internal mechanics of the crack formation and accumulation of damage by monitoring the joint openings and sliding.

\section{Evidence of accumulated damage in experiments and in 3D numerical models}

More than two-thirds of the building stock in Groningen consists of masonry structures comprising cavity walls (Crowley and Pinho 2017). In particular, the internal walls are made of a calcium silicate layer, while there is also an external layer, after an air gap, made of clay brick (see Fig. 1). This construction method is particularly vulnerable to seismic loading because of the weak connection between the two layers, the low axial load 


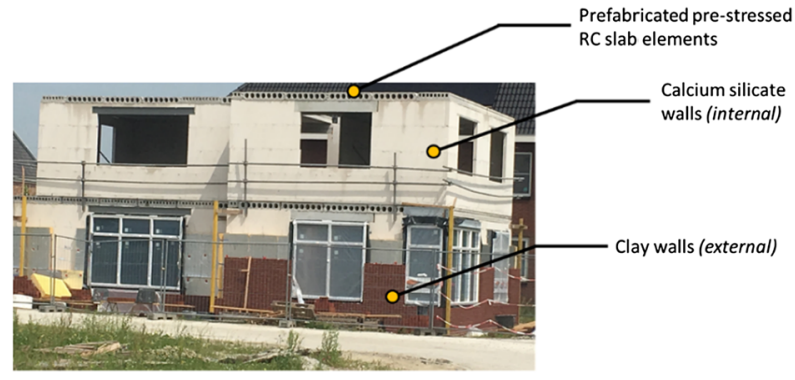

(a)

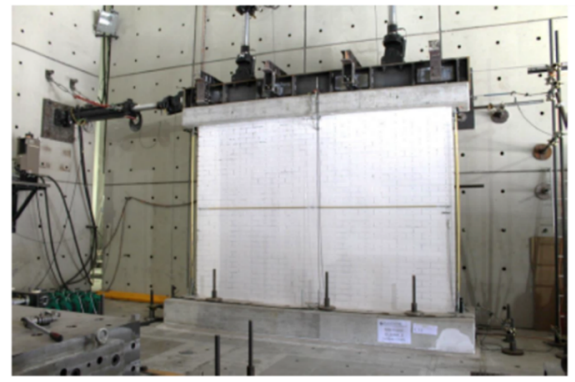

(c)

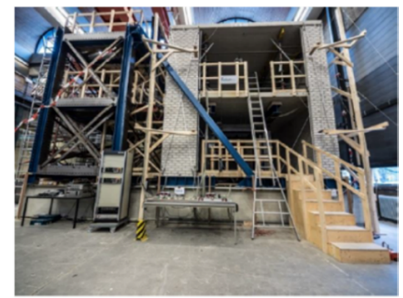

(b)

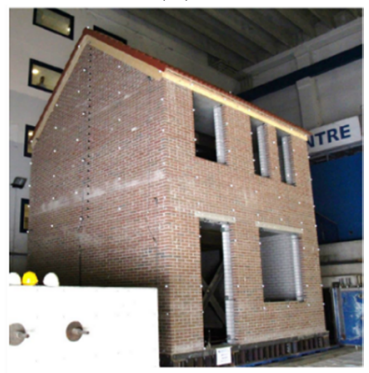

(d)

Fig. 1 a Typical masonry Groningen house under construction, b full scale cyclic test setup for Groningen houses (Esposito et al. 2017), c quasi-static in-plane calcium silicate wall specimen from Graziotti et al. (2015, 2016), and d full-scale cavity-wall test specimen on the shake-table from Graziotti et al. (2017, 2018)

on the external layer, the unusually large openings, as well as the high out-of-plane slenderness of the bearing walls. Quasi-static cyclic tests, component tests in compression, shear and combined actions, as well as full-scale shake-table tests have been conducted on Groningen-type structures in the laboratories at TU Delft, LNEC, University of Pavia and EUCENTRE. Results of some of these tests have been reviewed hereinafter in order to find experimental evidence on the accumulation of damage. A discussion has been provided in the next section.

\subsection{Reference to cumulative damage in masonry experiments}

The vast majority of the research on masonry provides only indirect information about the accumulation of damage as it does not constitute the main topic of the research in those studies. There are only a handful of publications that majorly focus on detecting and quantifying the damage accumulation. Tomor et al. (2013) investigated the deterioration process of brick masonry through small-scale laboratory tests under compression and shear. With the help of acoustic emission methods, they identified three different stages of accumulation of damage, i.e. compaction, micro-cracking and macro-cracking for compression loading, but were not able to detect a trend of damage accumulation for shear loading. Tests conducted at TU Delft (Rots et al. 2017) on masonry specimens resembling Groningen structures showed that the compressive behaviour is highly nonlinear starting from very 
low stress levels (i.e. 10\% of the strength and above). On the other hand, cyclic tests on a full-scale two-storey Groningen house resulted in residual structural cracks up to $1 \mathrm{~mm}$ width at $0.055 \%$ drift levels (Esposito et al. 2017).

Test data of the experiments conducted at EUCENTRE and LNEC were examined here as well in terms of damage accumulation. Three full-scale buildings were tested at EUCENTRE and LNEC on shake-tables. Several component and material wall tests were also conducted before the main full-scale shake-table tests. Repeated compression tests on masonry wallettes (Graziotti et al. 2015) demonstrated that there is a residual plastic deformation on the samples at $10 \%$ of the strength, and this deformation is close to the peak deformation attained in that loading half-cycle. The ratio of the residual displacement to the maximum displacement of the relevant half cycle decreased gradually (note that the residual displacement value increased in absolute terms) reaching up to $70 \%$ at the maximum load.

The cyclic tests on calcium silicate wall specimens (Graziotti et al. 2015) were quite useful to better understand the potential of damage accumulation in masonry. Three of such wall tests were executed at EUCENTRE by using typical brick and mortar used in the Groningen construction practice. A considerably large number of Groningen buildings consist of cavity walls in which only the interior leaf is bearing the vertical loads coming from the slabs. Therefore, the tests at EUCENTRE (Graziotti et al. 2015) were conducted for in-plane loading on the inner leaf that would suffice representing the real response of Groningen houses, while both leaves were included in the out-of-plane shake-table tests. In the latter, which is not the scope of this paper, the presence of the outer leaf can alter the overall response. Note that the single walls tested and used here in this paper, as well as the full-scale Groningen houses tested on shake-table, had similar material properties. The 3D full-scale Groningen houses were also built in the laboratories at EUCENTRE and LNEC with the same techniques by a specialised Dutch team, so that they resemble as much as possible the real structures in Groningen. The results obtained from the individual wall tests, thus, can be used with enough confidence when investigating the in-plane response of Groningen houses with cavity walls.

One of the three specimens was $4 \mathrm{~m}$ long and $2.35 \mathrm{~m}$ high, resembling a shear-dominated wall. The other two specimens were slender, $1.1 \mathrm{~m}$ wide and $2.35 \mathrm{~m}$ high, resembling flexure-dominated walls. One of the slender specimens experienced a premature failure, thus the results of that experiment were not useful. The first cycles of the lateral loading for the remaining two specimens are provided in Fig. 2a in a normalized format, where force and lateral deformation of the wall specimens in the first loading cycle have been divided to the overall wall strength and to the wall yield displacement, respectively. As readily seen (Fig. 2a), the first loading cycle is approximately $25-30 \%$ of the strength of the wall, resulting in $10-15 \%$ of the yield displacement. Both specimens exhibited residual displacement approximately $2-3 \%$ of the yield displacement at zero load crossing, thus at $20 \%$ of the peak displacement of the first cycle. This is a highly plastic behaviour, at component level, even though it is only the first loading cycle with relatively small forces and displacements attained.

In agreement with the observations on the quasi-static calcium silicate wall tests, the sequential dynamic tests on the full-scale 2-storey terrace house specimen under two different earthquake records (Fig. 2b, c) resulted in accumulation of residual displacements too. The 3D full-scale test specimen, similar to the Groningen cavity-wall terrace houses, consisted of internal and external walls. These two layers had a slight interaction but they majorly respond to the ground shaking as independent systems. In particular, both the inner and outer veneer walls were measured to have $0.18 \mathrm{~s}$ fundamental period of vibration 


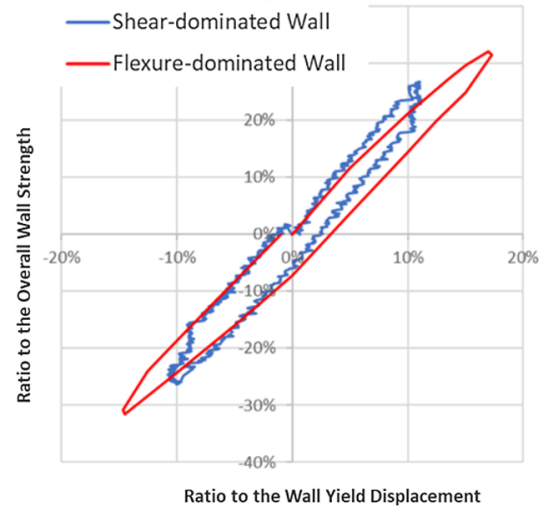

(a)

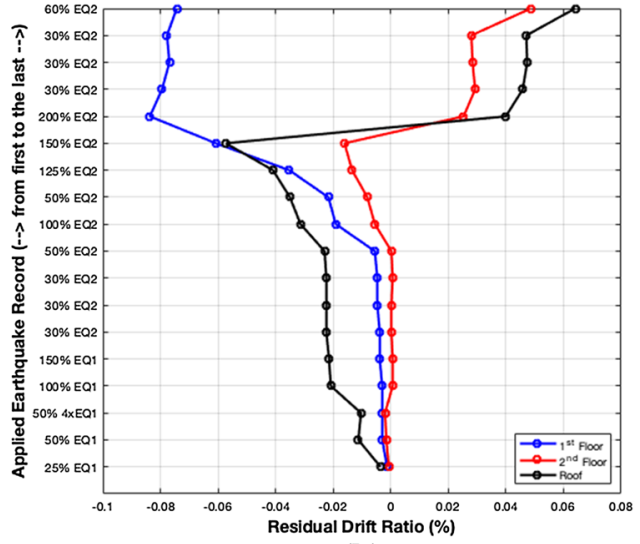

(b)

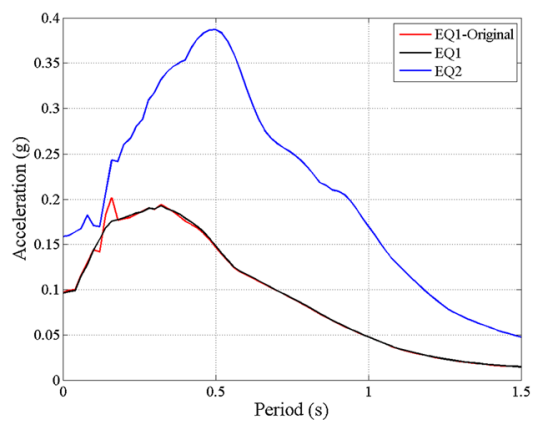

(c)

Fig. 2 a First cycles from the quasi-static wall tests on calcium silicate specimens (modified from Graziotti et al. 2015), b residual displacements from sequential shake-table tests on the full-scale specimen (modified from Graziotti et al. 2017, where 'y' axis shows the sequentially applied earthquake records starting from the bottom, 25\% EQ1, and ending with the top, 60\% EQ2), and $\mathbf{c}$ the acceleration spectra of the EQ1 and EQ2 records used in the shake-table tests (taken from Graziotti et al. 2015)

although they are rather independent from each other. The damage pattern of the test structure was reported as combination of in-plane and out-of-plane cracks on the walls. In-plane cracks were concentrated on spandrels and on internal walls, while the outer layers were subjected to out-of-plane cracks mostly. The walls in the loading direction suffered diagonal cracks at spandrel levels. The in-plane cracks were mostly diagonal shear cracks. Outof-plane cracks were evident on the walls perpendicular to the loading direction. The damage pattern of the roof gable wall was clearly an out-of-plane response. More details and relevant figures of damage can be seen in Graziotti et al. $(2015,2017)$.

In Fig. $2 b$ the results from 18 sequential tests with varying earthquake scaling from 25 to $200 \%$ are presented. The EQ1 in this set of tests refers to an earthquake record with $0.1 \mathrm{~g}$ PGA while the EQ2 is a record with $0.16 \mathrm{~g}$ PGA (random vibration test results are removed from the original figure in Graziotti et al. 2017). The residual displacement from the sequential application of these earthquakes is not cumulative towards one direction, meaning that it changes sign during the experiments. For example, application of $150 \%$ of EQ2 resulted in $4.5 \mathrm{~mm}$ residual displacement at roof while the next applied record, 200\% of EQ2, resulted in $3 \mathrm{~mm}$ residual displacement in the opposite direction. Observations on 
the crack width at the first and second floor of the same specimen were also presented in Graziotti et al. (2015), where a continuously increasing pattern in crack width was revealed, suggesting that the cumulative damage may manifest itself in different forms when residual system displacements or specific structural cracks are monitored. This is an issue that will be addressed in more detail later in this paper.

\subsection{Evidence of damage accumulation in 3D numerical analyses}

Two houses of different typology (Fig. 3), one real index building and one test structure typical of real structures in the Groningen gas field, were extensively studied by several researchers for determining the vulnerability of the structural inventory and thus the seismic risk in the region (van Elk and Doornhof 2017; Crowley and Pinho 2017). The two dominant types of residential structures in the area are the terrace and detached houses. Terrace houses are unreinforced masonry buildings, typically two to three floors, constructed with cavity walls as explained before. Detached ones are the older style houses, mostly built with solid unreinforced masonry walls, still of two to three floors typically. In an attempt to derive information for the fragility and consequence model for Groningen gas field, Mozayk (2017) presents 3D analysis results of two typology buildings: Nieuwstraat 8 and LNEC-BUILD1. Nieuwstraat 8 is an unreinforced masonry detached house with timber attic and roof diaphragms, built around 40s. LNEC-BUILD1 is a full-scale URM cavity-wall house specimen tested at LNEC (Tomassetti et al. 2017). In the study by Mozayk, the two buildings were modelled by using the applied element approach (Meguro and Tagel-Din 2000) and subjected to nonlinear time-history analyses by using 11 records selected to cover a range of intensities in terms of AvgSa (Kohrangi et al. 2017), Arias Intensity (Arias 1970), PGA and spectral acceleration at $0.1 \mathrm{~s}$. The horizontal component of the selected records was applied in the weak direction of these structures, while each acceleration record was imposed individually and not sequentially. Details of the modelling assumptions, as well as the analyses results can be found in Mozayk (2017).

The analyses results, the digital data of which were kindly provided by Mozayk to the authors, were presented in terms of in- and out-of-plane displacements at the gable wall level. Individual time-history analysis results were then re-processed by the authors producing plots of the residual gable wall drift ratio versus maximum drift ratio attained in the analyses for both in-plane and out-of-plane structural response (Fig. 4). Unit value
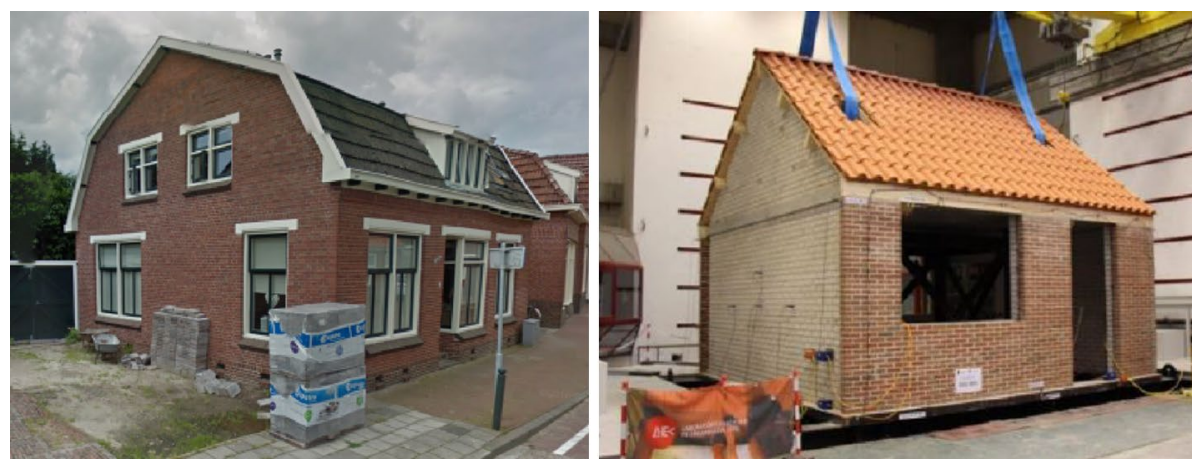

Fig. 3 Typology buildings analysed by Mozayk (2017): Nieuwstraat 8 index building (left) and LNECBUILD1 (right) 

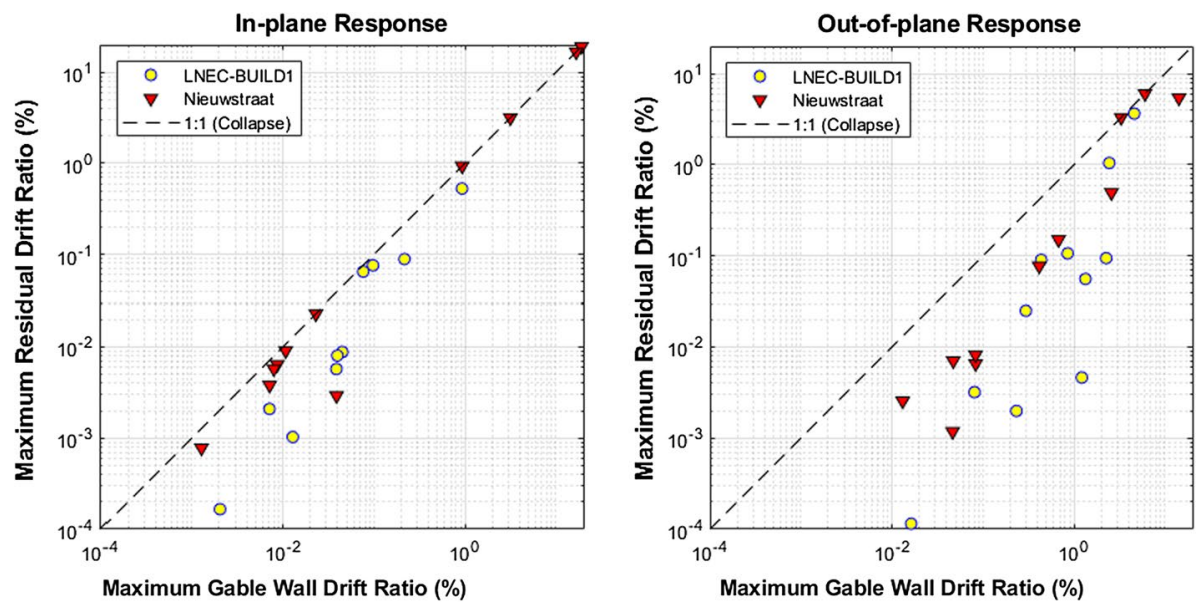

Fig. 4 Comparison of the residual top drift ratio from each individual time history analysis versus the maximum top drift ratio attained during that analysis, based on the data taken and re-processed from Mozayk (2017)

ratio of residual drift to the maximum drift manifests collapse as the structure reaches a certain excessive displacement at the end of the analysis and remains there without being able to re-centre at all. The consistently smaller residual displacements in the out-of-plane response reflect the re-centring ability of masonry walls under out-of-plane actions thanks to the vertical loads and self-weight, behaviour that is even more evident in slender walls, as supported by the very low out-of-plane residual drifts of the LNEC-BUILD1 that consists of slender cavity walls. Concluding, every individual earthquake record can induce significant residual deformations on the analysed typology buildings, suggesting that repetition of such earthquakes would lead to accumulation of damage and change in stiffness and strength characteristics of similar buildings.

\section{Cumulative damage on SDOF models}

MDOF properties of a real building can be coined into a single SDOF curve after a number of assumptions and simplifications are made. Generating an SDOF system that would respond similarly to its MDOF counterpart in terms of top displacement and base shear force constitutes a common procedure acceptable for the sake of simplification of analysis. SDOF models representing real buildings are often preferred for faster yet efficient way of deriving results from large number of time-histories analyses. Previous efforts of modelling cumulative damage on SDOF models (Aschheim and Black 1999; Elnashai and Di Sarno 2008; Di Sarno 2013; Mouyiannou et al. 2014; Hatzigeorgiou and Beskos 2009; Dais et al. 2017) show that such simplified models are not able to accurately capture the accumulation of damage if sequential time-history analyses are run, unless stiffness and strength degradation issues are properly addressed. Even in this case, the start of the next earthquake from the point the previous one has left the structure is not a straightforward issue since the residual displacements from a previous earthquake are numerically wiped, thus "forgotten", once larger displacements are attained in the next earthquake. A user 
intervention is needed to accurately model the sequence in the accumulation of residual displacements. Mouyiannou et al. (2014), for example, proposed an approach where the SDOF model is subjected to cyclic displacement reversals until the target displacement that represents the accumulation of damage is attained, then further earthquake records were applied in the model.

Three typology buildings from Groningen gas field were modelled as SDOFs in this work to investigate the possibilities of modelling the cumulative damage. OpenSees (McKenna et al. 2000) was used for the analyses, and, as suggested by Crowley and Pinho (2017), the "Hysteretic Uniaxial Material" was employed for modelling the SDOF response. Crowley and Pinho (2017) calibrated the SDOF backbone curves by using dynamic hysteresis loops representing the peak base shear of each analysis and the corresponding attic floor displacement (i.e. the highest level of the building). For further details on the calibration of the SDOF models as well as other relative assumptions, such as damping and hysteresis loop cyclic parameters, the reader is referred to Crowley and Pinho (2017). The index buildings used were the Julianalaan 52 (J52) and Badweg 12 (B12), as well as the Nieuwstraat 8 (NS8) mentioned before. J52 and B12 are URM terrace houses with cavity walls, wooden roofs and concrete floors. J52, B12 and NS8 have effective SDOF periods of 0.17, 0.13 and $0.19 \mathrm{~s}$, respectively.

The parameters for the SDOF models, calibrated by Crowley and Pinho (2017) and referred to as CP17 backbone curve, had to be slightly modified for this study. If the original CP17 backbone curve was used (Fig. 5a), a fully elastic response would be obtained without any plastic deformations, residual displacements or hysteretic energy consumption when Groningen records are applied, as explained further in the paper. The initial force-displacement branch of URM response is assumed linear in the CP17 backbone curve for the sake of simplicity, however in reality the response is often nonlinear even in

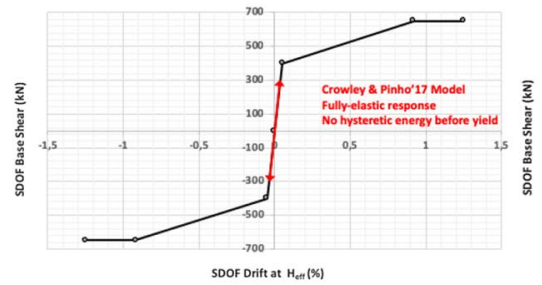

(a)

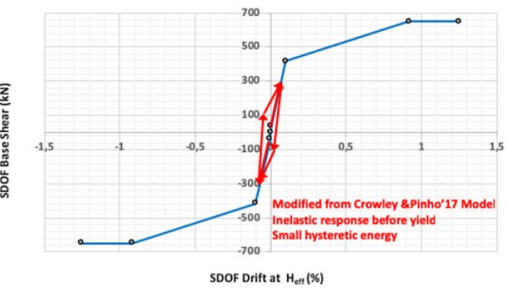

(b)

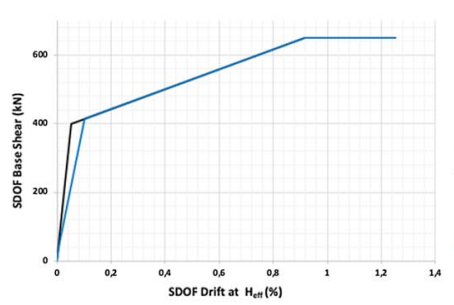

(c)

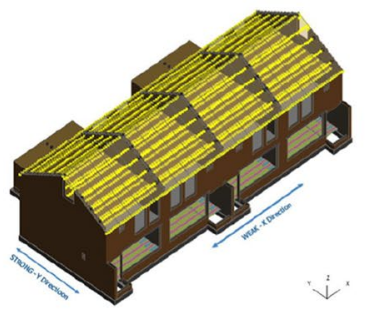

(d)

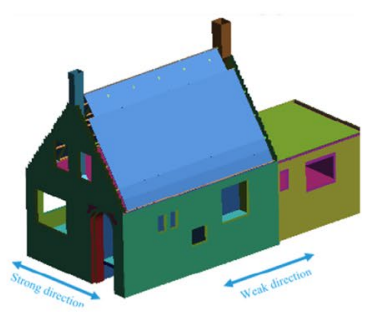

(e)

Fig. 5 a An example SDOF backbone curve from Crowley and Pinho (2017), b modified SDOF backbone to obtain plastic deformations and hysteretic energy consumption even in attained forces smaller than the yield, c comparison of the original Crowley and Pinho' 17 SDOF curve with the modified curve, d index building Julianalaan 52 and e index building Badweg 12 (please note that the other index building, NS8, was already shown in Fig. 3) 
the small pre-yield load and displacement amplitudes as discussed in this paper earlier (see Fig. 2a). In order to represent this aspect of URM structures, the first branch of the CP17 backbone has been modified (Fig. 5). The yield force of the fully elastic branch in the CP17 model is reduced down to its 1/10th (see Fig. 5c for comparison). Such an ad-hoc assumption, not relying on experimental evidence due to lack of such evidence at first hand, has been made for the sake of convenience given the parametric nature of this exercise.

The SDOF models comprise a weightless rigid stick with the SDOF effective mass on top, while the force-displacement response of the mass is lumped in a rotational spring at the bottom. A script was used to modify the OpenSees input model at the end of each analysis so that the residual displacement from the last analysis was inserted into the next model as a coordinate change of the top of the SDOF system. Additionally, strength degradation was taken into account by finding the ductility demand from the latest analysis and computing the damage coefficient, which fed into the software for modifying the properties of the SDOF hysteresis loop. The damage depends on the ductility $\mu$ and the damage coefficient $\mathrm{D}$ through is $\mathrm{D}(\mu-1)$. Four different values of $\mathrm{D}$ were tested: 0 (i.e. no damage accumulation during the cycles), $0.005,0.010$ and 0.015 , for each one of which hysteresis loops were obtained similar to those in Fig. 7. The North component of the MID1 record of Huizinge Earthquake, August 2012, and the East component of the BGAR record from the January 2018 Zeerijp Earthquake (Fig. 6) were used for the analyses. Two different records were used so that it is clarified whether there is a dependency on the imposed record. It is
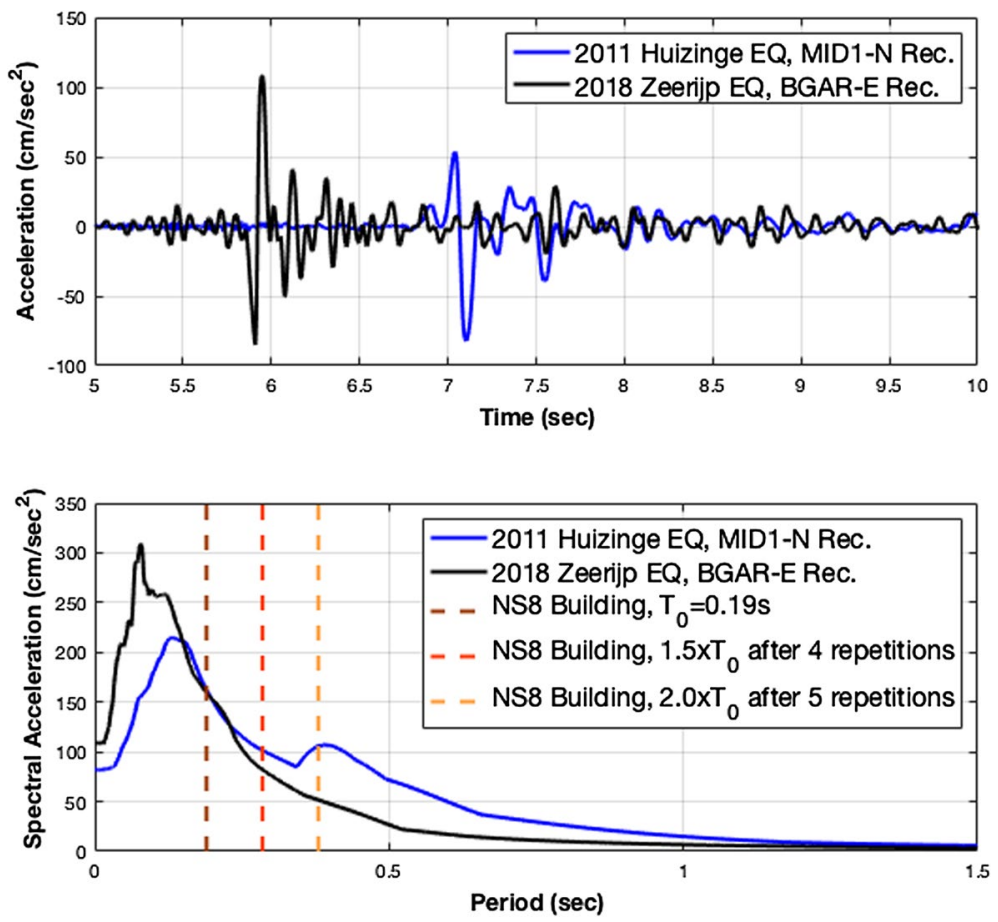

Fig. 6 Acceleration time histories of the two Groningen earthquake records used for analyses (top), and comparison of their 5\% damped elastic acceleration response spectra together with the change in fundamental period of NS8 building SDOF model (bottom) 


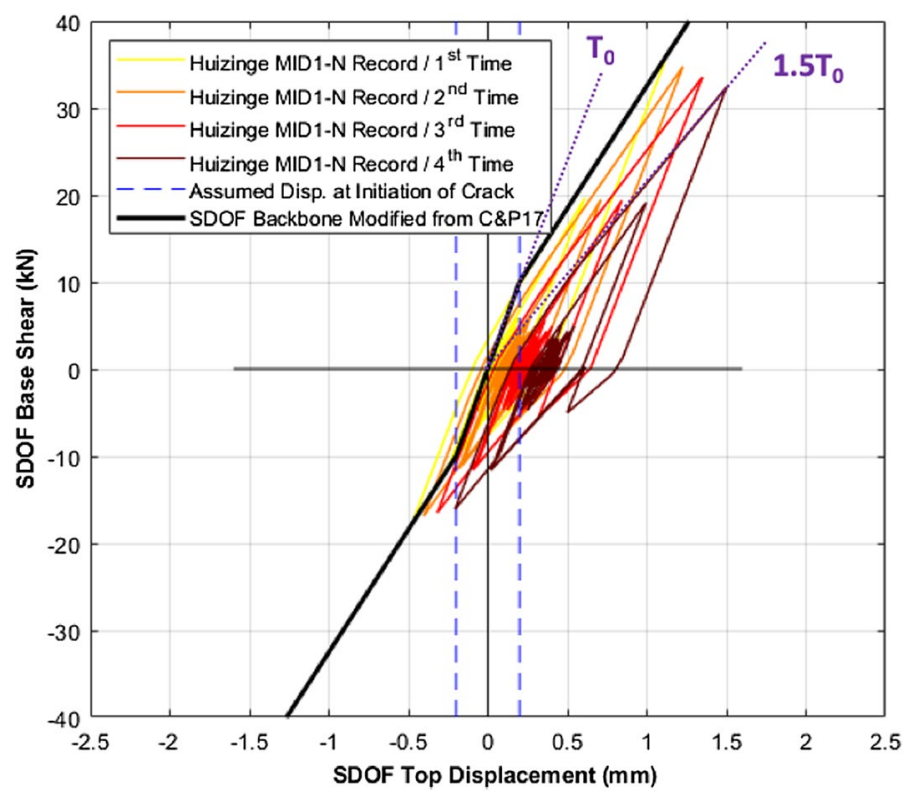

Fig. 7 Response of the SDOF model of Nieuwstraat 8 (NS8) to Huizinge earthquake (2012) MID1 record N component sequentially 4 times, with a damage coefficient $\mathrm{D}$ of 0.015

found that when strength degradation is considered, the relationship between the earthquake sequence and the residual damage is not linear, in fact the damage is fast increasing as more earthquakes applied on the structure. On the contrary, this relation is perfectly linear when the strength degradation is ignored. One of the plausible explanations for the high record-sensitivity of the accumulation of damage can be the match between the dynamic properties of the structural model and of the applied record. Although the BGAR-E record from the Zeerijp Earhquake has higher PGA $(0.111 \mathrm{~g})$ than that of the MID1-N record from the Huizinge Earthquake $(0.084 \mathrm{~g})$, their elastic spectral acceleration responses are identical at $0.19 \mathrm{~s}$, which is the fundamental period of vibration of the NS8 SDOF model. The SDOF fundamental period elongates as nonlinearities develop and as more residuals accumulate. An example is shown in Fig. 7 where the effective period of vibration of the SDOF model increases $50 \%$ after the same earthquake is applied 4 times. The fundamental period is doubled, for example, after the Huizinge record is applied 5 times on the NS8 SDOF. The initial and the elongated periods of the NS8 model can be seen in Fig. 6 (bottom), where the spectral demand of the Huizinge record is twice that of the Zeerijp record.

It is underlined that the results obtained are only parametric since there is no experimental evidence that would allow to calibrate the strength degradation of the SDOF model of those index buildings. The results exhibit accumulation of damage towards a certain direction, as well as degradation of strength with increasing number of earthquakes. Even if the exact same earthquake record is applied, the residual damage, which is the residual displacement of the SDOF system, is nonlinearly increasing. Figure 8 presents analyses conducted by applying the same earthquake record 10 times on the SDOF models for the three index buildings.

Although the exercise presented here is parametric, the assumption of a maximum damage coefficient (D) equal to 0.015 , used in producing Fig. 7 , has been cross-checked. A 

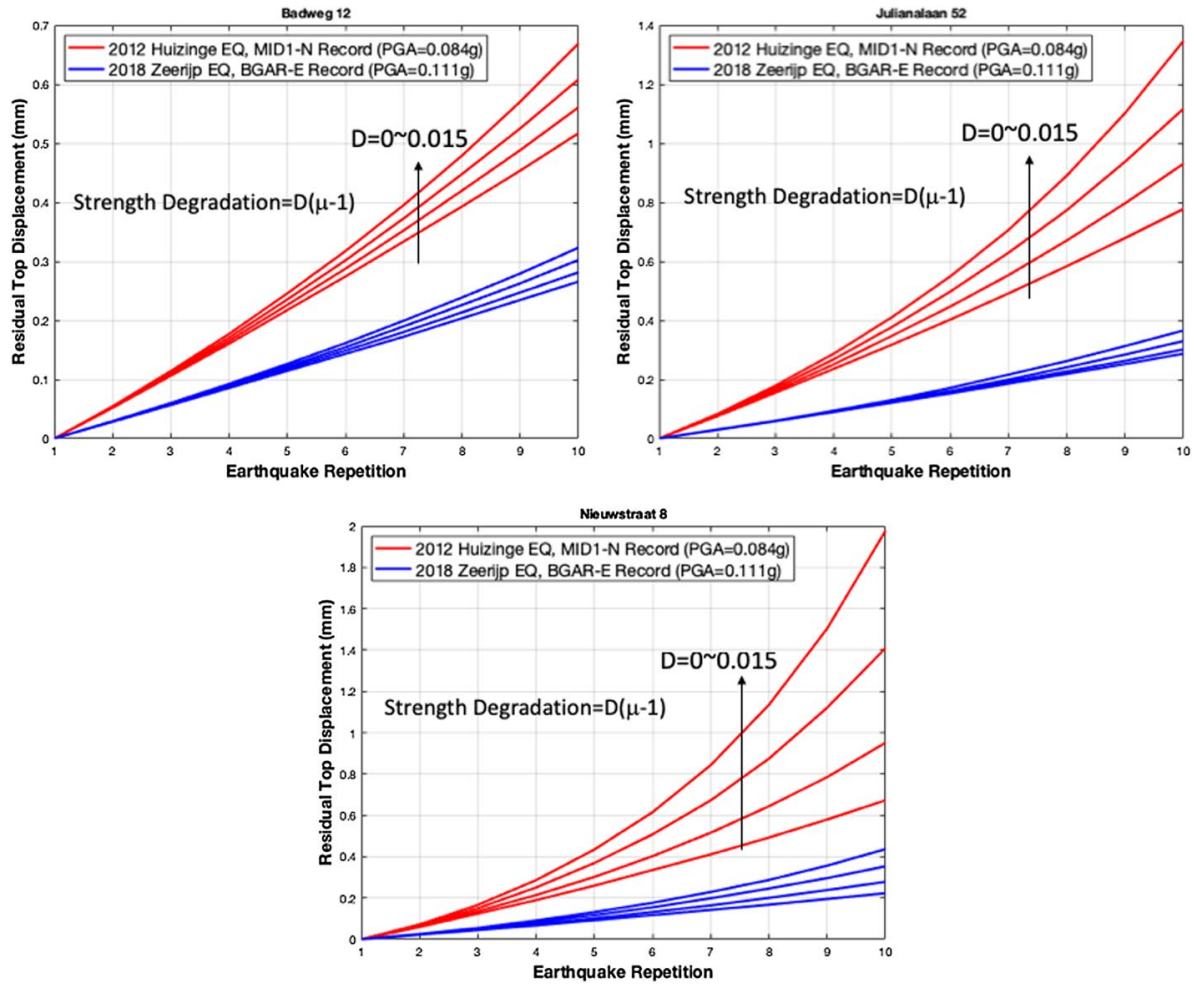

Fig. 8 Residual top displacement of the SDOF models for 10 times repeated 2012 Huzinge (MID1-N component) and 2018 Zeerijp (BGAR-E component) records for the index buildings Badweg 12 (top-left), Julianalaan 52 (top-right) and Nieuwstraat 8 (bottom)

recent study by Korswagen et al. (2018) presents results of tests on a Groningen-type unreinforced masonry wall with a large opening, very similar to the example walls analysed further in this work. They applied repeated loads, only in positive direction (i.e. not cyclic between positive and negative displacements), and obtained strength drops 1.3-3.8\% when the very same load is applied 3 times consecutively. For the maximum damage coefficient $(\mathrm{D}=0.015$ ) used herein, a strength drop of $4.7 \%$ (from $34 \mathrm{kN}$ in the first time to $32.4 \mathrm{kN}$ in the 3rd time, shown in Fig. 7) was obtained, a reasonable value considering that the response was result of an earthquake motion that includes several cycles, as opposed to the tests of Korswagen et al. (2018) with 3 cycles per loading level.

It was shown in the exercise here that, in overall, SDOF models can be useful for detecting tendencies in cases that more complicated analyses are not feasible. The applicability of the results in broader sense, on the other hand, is rather limited. The major drawback of using SDOF models for detecting damage accumulation in URM is the need for calibration based on experimental evidence on damage and cyclic degradation. More elaborate analyses were conducted as given hereinafter for obtaining insight into the internal damage distribution on the wall as motions are applied in sequence. 


\section{Cumulative damage on discrete-element wall models}

\subsection{Overview of the discrete-element model}

In order to overcome the issues related to the use of SDOF models explained previously, detailed models were created employing discrete-element modelling (DEM) approach in UDEC software (Itasca 2011), a tool based on discontinuous modelling that can simulate the response of discontinuous media subjected to either static or dynamic loading. When used to model brickwork structures, the bricks are represented as an assemblage of rigid or deformable distinct blocks which can take any arbitrary geometry. Rigid blocks do not change their geometry as a result of any applied loading and are mainly used when the behaviour of the system is dominated by the mortar joints. Deformable blocks are internally discretised into finite difference triangular zones and each element responds according to a prescribed linear or non-linear stress-strain law. These zones are continuum elements as they are defined in the finite element method (FEM). Mortar joints are represented as zero thickness interfaces between the blocks. These interfaces can be viewed as interactions between the blocks and are governed by appropriate stress-displacement constitutive laws. Interaction between the blocks is represented either by sets of point contacts or by sets of edge to edge contacts, with no attempt to obtain a continuous stress distribution through the contact surface. The mechanical interaction between the blocks is simulated at the contacts by spring like joints with normal and shear stiffness.

As in the Finite Element Method, the unknowns are the nodal displacements and rotations of the blocks. However, unlike FEM, DEM is a dynamic process and the unknowns are solved explicitly by the differential equations of Newton's Second law of motion at all bricks or nodes and the force-displacement law at all contacts. The force-displacement law is used to find the contact forces from known displacements, while Newton's second law gives the motion of the blocks resulting from the known forces acting on them (Fig. 9). In this way, large displacements along the mortar joints and the rotations of the brick elements are allowed with the sequential contact detection and update of tasks automatically. Furthermore, DEM approach can model both static and dynamic load effects. The static solution is achieved by artificial damping similar to the dynamic relaxation method where the equations of motion are damped to reach the equilibrium state. Also, the DEM approach can employ time-stepping algorithms either in real time scale or as a numerical device to solve quasi- static problems (Itasca 2011). For a full description of modelling masonry structures using the discrete element method, the reader is referred to Sarhosis and Sheng (2014) and Sarhosis et al. (2015).
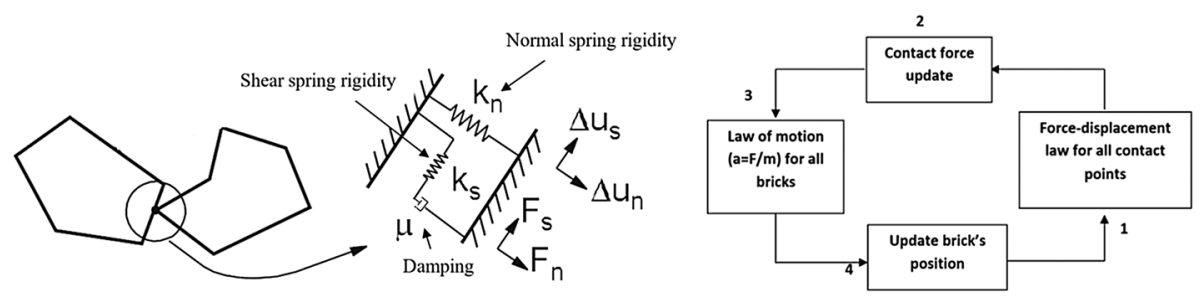

Fig. 9 Mechanical representation of contact between blocks (left) and the simplified calculation cycle for rigid blocks (right) 


\subsection{Experiment used for calibration and the numerical model}

One of the walls tested by Graziotti et al. (2015) was used here for parametric analyses. It is reminded that the wall had dimensions of $4.0 \mathrm{~m}$ width and $2.75 \mathrm{~m}$ height, representing a shear-dominated wall (Fig. 1c). The specimen was left free-to-rotate on the top creating a cantilever condition. A constant vertical stress of $0.3 \mathrm{MPa}$ was applied during the tests, kept fairly constant by two vertical actuators. The wall material was calcium silicate and cement mortar, representing the terrace houses with cavity walls built in the region in the post-war time. The calcium silicate layer is the internal leaf bearing the vertical loads from the slabs in the Groningen construction practice.

In the numerical model, the vertical edges of the wall panel were left free. Gravitational load due to self-weight was also imposed to the model in addition to vertical pre-compression equal to $0.3 \mathrm{MPa}$ assigned on the top of the wall in line with the experimental set up. The mass of the system used in the dynamic analyses consists of the wall self-weight as well as of the distributed mass on the top of the wall coming from the load representing the vertical pressure. Initially, the model was brought into a state of equilibrium under its own self-weight and then the seismic loads were assigned. A geometric model to represent the wall panel tested in the laboratory was constructed in UDEC software. Each brick of the masonry wall panel was represented by deformable blocks separated by zero thickness interfaces at each mortar bed and perpendicular joint. To allow for the $10 \mathrm{~mm}$ thick mortar joints in the real wall panels, each deformable block was based on the nominal brick size increased by $5 \mathrm{~mm}$ in each face direction resulting in a model block size of $225 \mathrm{~mm} \times 102.5 \mathrm{~mm} \times 75 \mathrm{~mm}$. A typical geometry of the wall panel developed in the software is shown in Fig. 10.

The analyses were conducted first on the solid wall with identical properties with the tested specimen. After the solid wall model was calibrated to fit the response of the tested wall (Graziotti et al. 2015), two more wall models were generated by creating a large opening of $2.5 \mathrm{~m} \times 2.0 \mathrm{~m}$ symmetrically (Fig. 10, middle) and asymmetrically (Fig. 10, right). Such large openings on the house façade are quite common in the building inventory within the Groningen gas field. The solid wall model had natural frequency of $16 \mathrm{~Hz}$, while the frequency of the perforated models was approximately $5 \mathrm{~Hz}$. The models were subjected to sinusoidal acceleration loading with varying amplitude between $0.025-0.1 \mathrm{~g}$ and frequencies of 1,5 and $16 \mathrm{~Hz}$.

Though modelling the bricks as deformable blocks allows any deformation to occur both in the blocks and in the joints, it was assumed that the bricks would exhibit linear stress-strain
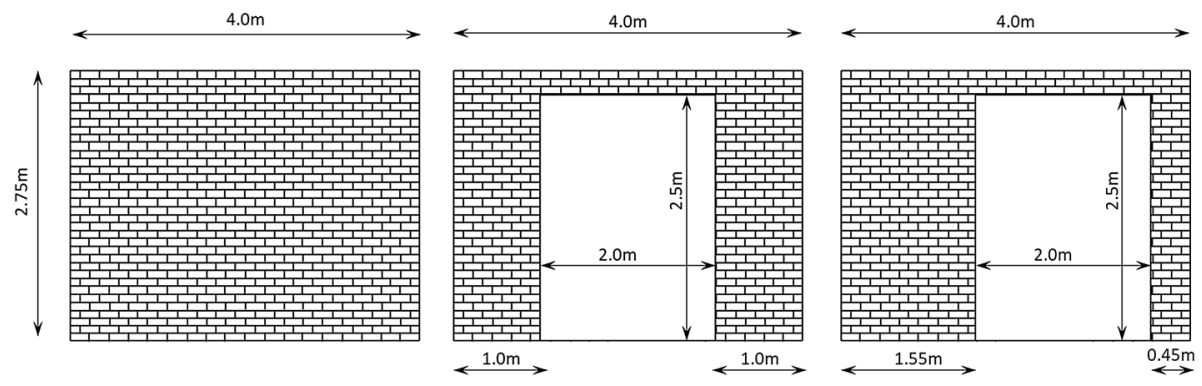

Fig. 10 Geometric models developed in UDEC: wall panel with no opening (left), wall panel with symmetric opening (middle), and wall panel with asymmetric opening (right) 
behaviour and that opening and slip along the mortar joints would be the predominant failure mechanism. Block parameters required by the software to represent the behaviour of the bricks are: density (d), elastic modulus (E), shear modulus $(\mathrm{G})$ and Poisson's ratio (v) of the bricks. The mortar joints represented by interfaces were modelled using the elastic-perfectly plastic Coulomb slip-joint area contact option in the software. This provides a linear representation of the mortar joint stiffness and yield limit based upon elastic normal $\left(\mathrm{J}_{\mathrm{kn}}\right)$ and shear $\left(\mathrm{J}_{\mathrm{ks}}\right)$ stiffness, frictional $\left(\mathrm{J}_{\text {fric }}\right)$, cohesive $\left(\mathrm{J}_{\mathrm{coh}}\right)$ and tensile $\left(\mathrm{J}_{\text {ten }}\right)$ strengths, as well as on the dilation $\left(\mathrm{J}_{\mathrm{dil}}\right)$ characteristics of the mortar joints. In addition, if the bond tensile strength or shear strength is exceeded in the numerical calculation, then the tensile strength and cohesion are reduced to zero. In discrete element modelling, behaviour of masonry is highly influenced by the material parameters used (Sarhosis et al. 2014, 2015). The material properties for the numerical models used at this study are presented in Table 1 . The brick and mortar interface properties have been adopted from the experimental tests carried out in Pavia (Graziotti et al. 2015) and presented in Table 2.

The validation of the model was performed against the results of the experiment under cyclic horizontal in-plane load with incremental increase of the imposed displacements. The initial stiffness for the model is captured with accuracy (Fig. 11). Apart from the crack patterns (Fig. 11a, b), the cyclic response for the first three cycles have also been compared, where important parameters such as strength, unloading and reloading stiffnesses are captured fairly accurately (Fig. 11d). The hysteretic loop obtained from numerical analyses provides higher hysteretic energy dissipation by $12 \%$ (Fig. 11e) than the experiment, level that was deemed satisfactory. The match of the model to the very first cycles of the load-displacement curve is of prime importance for the purposes of this paper as the applied acceleration levels, up to $0.10 \mathrm{~g}$, do not mobilize the entire hysteretic behaviour of the wall. The levels of accelerations in the analyses were up to $0.25 \mathrm{~g}$ initially, but this caused collapse in the walls with large opening. This is basically why the analyses results with acceleration amplitude up to $0.10 \mathrm{~g}$ are presented here. This is a reasonable level of acceleration considering that the highest PGA ever recorded in Groningen gas field was $0.11 \mathrm{~g}$ in 2018 Zeerijp Earthquake (Fig. 6).

\subsection{Discrete-element analysis results}

The discrete-element analysis results are presented in Fig. 12. The results were processed with respect to the overall wall top displacement in the lateral loading direction, joint slip and joint opening. The complete set of plots cannot be presented here due to lack of space. A consistent

Table 1 Properties of the masonry units used for the development of the computational model

\begin{tabular}{lll}
\hline Elastic modulus of brick $\left(\mathrm{N} / \mathrm{m}^{2}\right)$ & Bulk modulus $\left(\mathrm{N} / \mathrm{m}^{2}\right)$ & Shear modulus $\left(\mathrm{N} / \mathrm{m}^{2}\right)$ \\
\hline $5.20 \times 10^{9}$ & $2.90 \times 10^{9}$ & $2.16 \times 10^{9}$ \\
\hline
\end{tabular}

Table 2 Properties of the joint interface for the development of the computational model

\begin{tabular}{llllll}
\hline $\begin{array}{l}\text { Joint normal } \\
\text { stiffness }\left(\mathrm{N} / \mathrm{m}^{3}\right)\end{array}$ & $\begin{array}{l}\text { Joint shear stiff- } \\
\text { ness }\left(\mathrm{N} / \mathrm{m}^{3}\right)\end{array}$ & $\begin{array}{l}\text { Joint friction } \\
(\text { degrees })\end{array}$ & $\begin{array}{l}\text { Joint tensile } \\
\text { strength }\left(\mathrm{N} / \mathrm{m}^{2}\right)\end{array}$ & $\begin{array}{l}\text { Joint cohesive } \\
\text { strength }\left(\mathrm{N} / \mathrm{m}^{2}\right)\end{array}$ & $\begin{array}{l}\text { Joint } \\
\text { dilatation } \\
(\text { degrees })\end{array}$ \\
\hline $12 \times 10^{11}$ & $4 \times 10^{11}$ & 32 & $0.21 \times 10^{6}$ & $0.24 \times 10^{6}$ & 0 \\
\hline
\end{tabular}




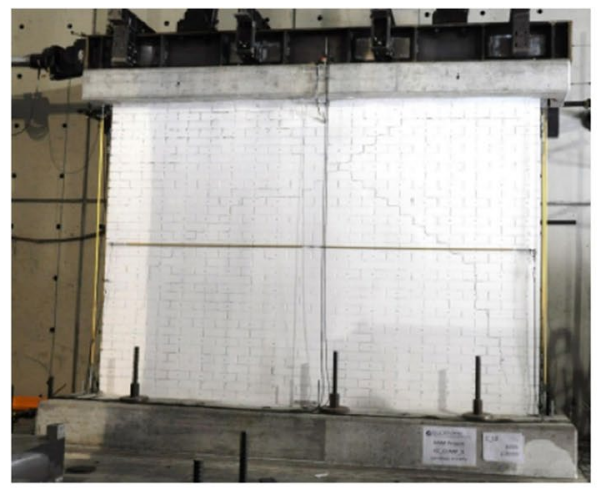

(a)

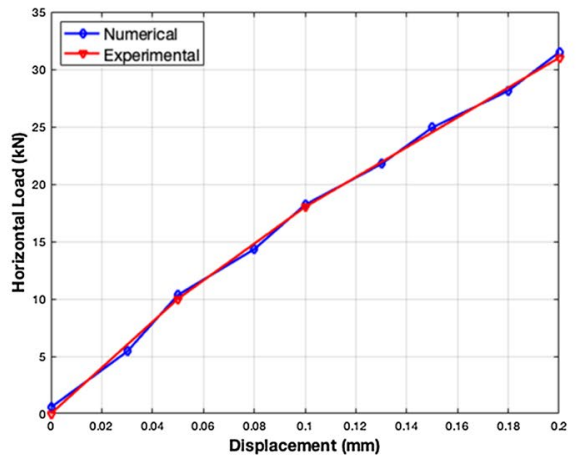

(c)

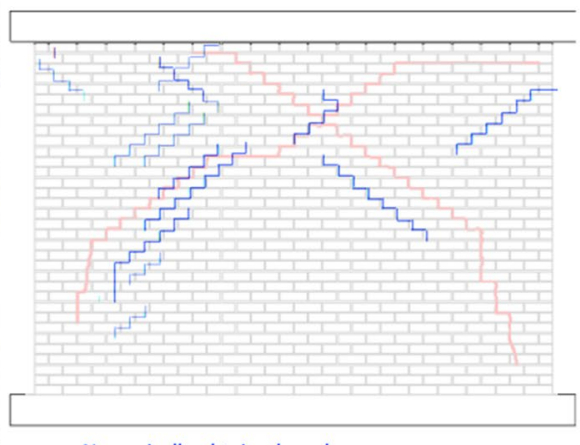

- Numerically obtained cracks

- Experimentally observed cracks

(b)

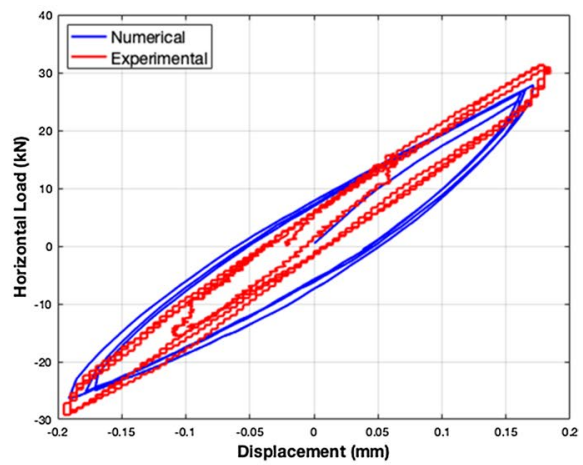

(d)

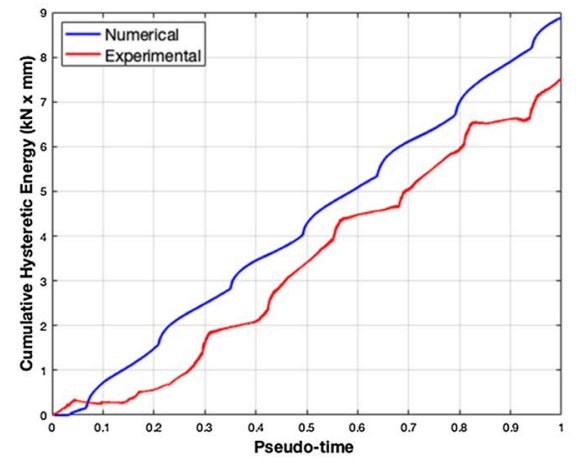

(e)

Fig. 11 Comparison of experimental against numerical results in terms of $\mathbf{a}, \mathbf{b}$ crack pattern observed, $\mathbf{c}$ the initial stiffness for the squat wall test, $\mathbf{d}$ the first loading cycles, and $\mathbf{e}$ cumulative hysteretic energy for the first cycles shown in $\mathbf{d}$

trend was not evident in the top displacement plots. For example, the residual top displacement is sometimes higher in smaller acceleration amplitudes or periodic loads with higher accelerations result in zero residual, while loads with smaller accelerations end up with a large 
residual. This finding is in line with the experimental results presented after the Pavia fullscale shake-table tests (see Fig. 2).

Due to the reasons explained so far, focus was placed on the crack monitoring in the discrete-element analysis results. The cracks can be monitored during the analyses either as "joint opening" or by "joint slip". The former is done by observing the trajectory of the initially coinciding two nodes. A crack is detected when the two nodes separate more than $0.1 \mathrm{~mm}$, a limit assumed as the initiation of visible cracks (Giardina 2013), in a direction perpendicular to the mortar joint. "Joint slip", on the other hand, is the total length of the joints that slipped under shear stresses.

Joint slip and joint opening are two ways proposed here for measuring the damage in URM. The damage can be more clearly quantified by using crack geometrical properties via these two metrics. Joint slip plots, shown in Fig. 12, provide residual slips up to $10 \mathrm{~m}$ total length in the entire wall. These are sliding movements, that would be manifested in an actual wall as cracks. Joint slip in the numerical model is sliding of a joint above others, as happens in the case of shear failure of the bed joints. The largest crack lengths, as well as residual cracks, occur in the case of $5 \mathrm{~Hz}$ loading because the frequency of the loading coincides with the natural in-plane frequency of the wall model with openings. Asymmetric or symmetric openings present little difference in total maximum and residual joint slip. It should be noted that the joint slip can take negative or positive values, as sliding motion can be in the positive or negative direction in respect to the original position of a given node. As observed in Fig. 12 the cracks open and close while the total crack length oscillates during the shaking. The ratio of the maximum total crack length to the residual total crack length increases drastically as the acceleration amplitude increases. The ratio of the maximum total joint slip to the residual total joint slip is $14.0(14 / 1), 3.0(15 / 5)$, and 1.67 (15/9) for $0.025 \mathrm{~g}, 0.050 \mathrm{~g}$ and $0.100 \mathrm{~g}$ acceleration amplitudes at $5 \mathrm{~Hz}$, respectively, in the case of wall with asymmetric opening. The max to residual crack length ratio dropped from 14 to 1.67 (8.2 times) while the acceleration amplitudes increased only 4 times. It should be noted that the joint slip values for the solid wall were not meaningfully large and thus not reported here.

Unless a damage function is associated to the cyclic behaviour of the spring-like interface elements, models similar to the discrete element, such as micro-models with equivalent joint springs, or applied element models will not be able to provide any damage accumulation for joint opening and closing. This is because the slender parts of the walls, such as the piers on the sides of the openings in the example here, rock under lateral loads causing joint opening. The same joints, however, close back when the slender wall pier recentres and returns to its original or near-original position. In reality, because the crack surfaces are not smooth, crushed material remains into the cracks, small pieces dislocate and thus a small amount of accumulation does occur. In other words, cracks that open in the direction perpendicular to the joint plane are expected not to perfectly close and thus start from a non-zero state to the next cycle.

The results for joint opening are presented in Fig. 13. Similar to the joint slip results, the total crack lengths are much higher in case $5 \mathrm{~Hz}$ load is applied. The joint opening values presented are only positive, which represents the opening of a crack (i.e. negative values would mean units penetrating to each other). The ratios of the maximum total crack opening to the total residual crack opening are $5.2(1.30 / 0.25), 3.1(1.70 / 0.55)$ and 2.90 $(1.75 / 0.60)$ for the wall with the asymmetric opening for $0.025,0.050$ and $0.100 \mathrm{~g}$ acceleration amplitudes at $5 \mathrm{~Hz}$, respectively. Joint opening is a metric that is expected to be heavily influenced by rocking, a mechanism that dominates in the case of wall with openings. This is because of the slender piers formed on the two sides of the opening. Once the 

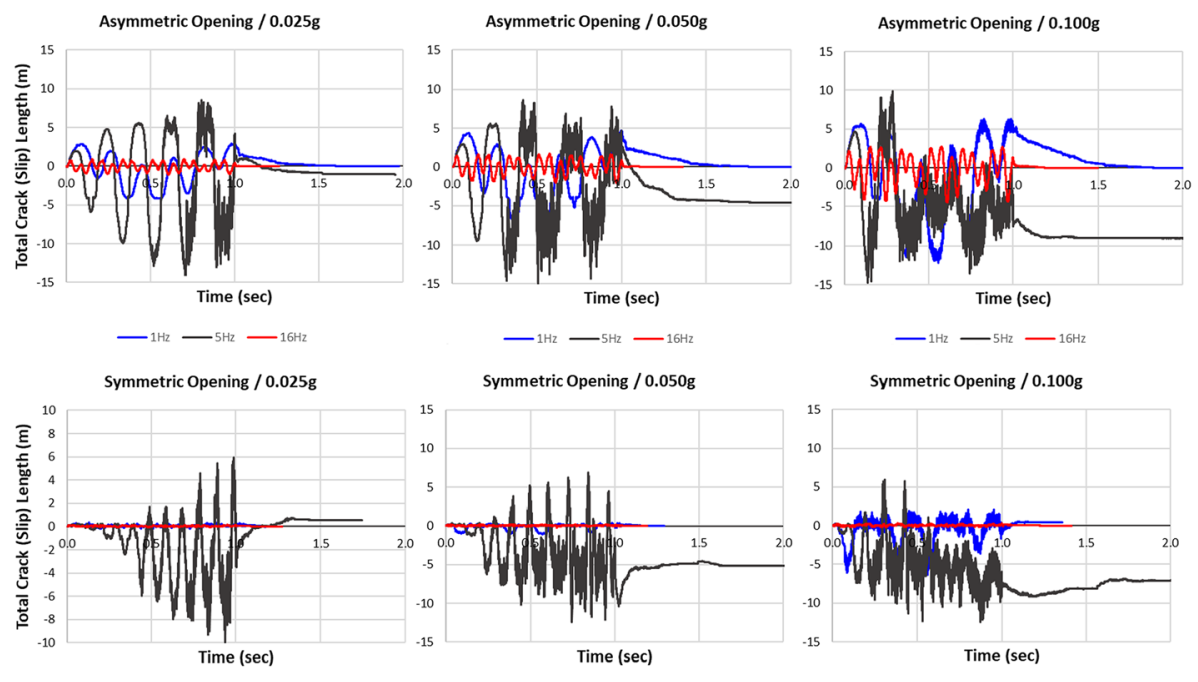

$-1 \mathrm{~Hz}^{2}-\mathrm{HHz}^{-16 \mathrm{~Hz}}$
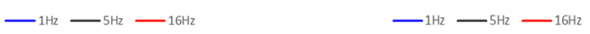

Fig. 12 Total crack (joint slip) length in the wall model with asymmetric opening (top), and symmetric opening (bottom) for sinusoidal acceleration waveform of $0.025 \mathrm{~g}, 0.05 \mathrm{~g}$ and $0.10 \mathrm{~g}$ amplitudes (solid wall results are not presented here because the model did not provide any meaningful results in terms of crack length)

rocking mechanism develops and the joint opening cracks are generated, the total crack length does not increase considerable when the acceleration amplitude takes higher values. Therefore, the ratio of the maximum total crack length to the total residual crack length does not practically increase when the acceleration loading amplitude is increased from $0.050 \mathrm{~g}$ to $0.100 \mathrm{~g}$. This finding suggests that the joint slip and joint opening are two distinct metrics that need to be monitored individually because of the expected influence of the damage mechanism of the wall on the type of crack.

\section{Conclusions}

Accumulation of damage under small and recursive earthquake motions becomes an important issue in case of induced seismicity, mainly because the relatively larger induced earthquakes trigger a damage-claim procedure, in which engineers are asked to detect if the present cracks and damages are caused by the specific earthquake or not. Already inherently difficult, the evaluation becomes cumbersome due to the ambiguity of the relevance to the already accumulated damages. Analytical tools may be a solution to shed light on the repeated earthquakes and their damage on the URM structures. This paper discussed abilities and limitations of the available analytical tools in respect to the evidence of damage accumulation reported in the experimental literature. The appropriateness of metrics of quantifying damage accumulation was also evaluated.

Relevant experimental evidence of damage accumulation on URM, reported in the literature, were summarized in order to first understand the background of the problem. Compression and shear tests, as well as full-scale shake-table tests on URM, were presented. It 
was shown by using the data of the full-scale shake-table tests that the cumulative damage does not monotonically increase in case overall structural parameters, such as top displacement or floor displacements, are monitored. Monitoring of cracks seems to be a better tool as cracks provide steady increase in measured damage when more earthquake loads are applied on the structure.

3D analyses results of Groningen index buildings have also been used for understanding the development of residual deformations in complicated numerical models. Results from models created by using applied element method have been re-processed. The available analytical results come from analyses with relatively high earthquake intensities, thus a direct correlation with the numerical models presented here and the obtained results was not possible. It was shown, however, that in relatively large acceleration levels, residual deformations become evident especially for the in-plane motion. Much less residual deformations were observed in the case of out-of-plane direction, possibly due to the re-centring ability of the slender walls used in the terrace houses in the Groningen gas field.

SDOF models with representative backbone curves were used in previous studies for detecting accumulation of damage. A similar effort has also been made here for understanding better the abilities of this approach. It was found that the residual displacement of the SDOF system in a previous event, a sign of accumulation of damage, is cancelled out in the next earthquake if the displacements exceed the residual displacement level. A user manipulation is needed to start the next analysis from a non-zero geometrical state. A method is proposed here for accounting for this geometrical change during the repeated earthquake loads.

Another issue with the use of SDOF models is the strength degradation. The damage accumulation is found to be quite sensitive to the amount of degradation and existing damage, but this is a parameter that needs calibration with experimental data. This is a difficulty for generalizing the results of a simplified SDOF model. The difficulty also stems
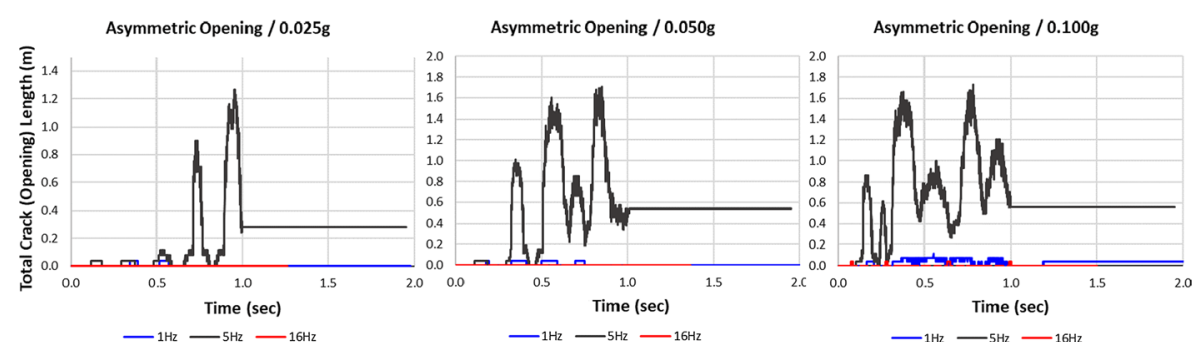

$-1 \mathrm{~Hz}-5 \mathrm{~Hz}-16 \mathrm{~Hz}$
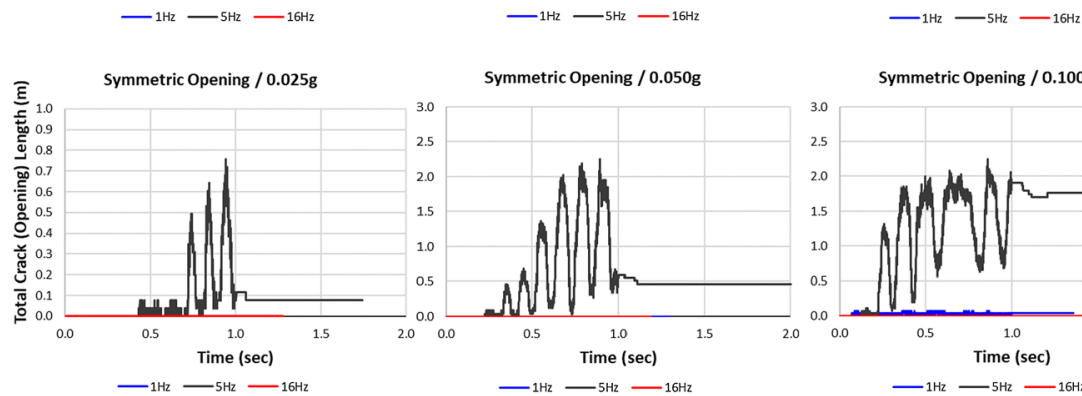

Symmetric Opening / 0.050g

Symmetric Opening / 0.100g
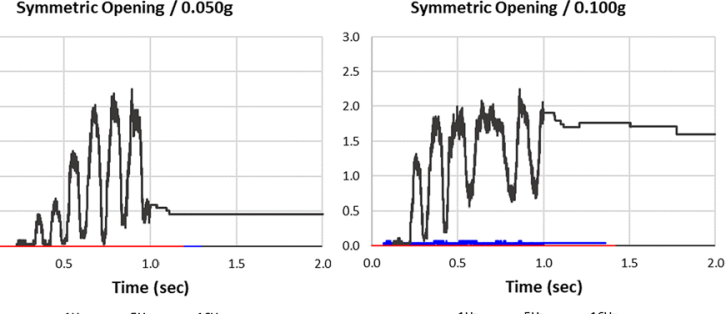

Fig. 13 Total crack (joint opening) length in the wall model with asymmetric opening (top), and symmetric opening (bottom) for sinusoidal acceleration waveform of $0.025 \mathrm{~g}, 0.05 \mathrm{~g}$ and $0.10 \mathrm{~g}$ amplitudes (solid wall results are not presented here because the model did not provide any meaningful results in terms of crack length) 
from the fact that the rate of accumulation of damage is extremely sensitive to the frequency content of the seismic records. In the exercise presented in this paper, a characteristic index building from Groningen (Nieuwstraat 8) was modelled as an SDOF system where degradation and damage are also represented parametrically. With an assumption of a reasonable level of damage potential, that is $\mathrm{D}=0.015$ associated to the SDOF hysteresis model, the effective period of the model is almost doubled when the MID1-N record from the Huizinge Earthquake of 2012 (M3.6) is applied 5 times consecutively. Although two different Groningen records with identical spectral acceleration demand at the initial period of the model were applied, i.e. records from Huizinge and Zeerijp events, the former caused accumulation of damage much faster than the latter. This was explained with the fact that, after applying each record 5 times consecutively, the spectral demand of the Huizinge record was twice that of the Zeerijp record.

Discrete element modelling approach is also used here for overcoming the difficulties of the SDOF models. A solid shear-dominated wall was modelled and initially calibrated against the experimental results. Two more walls, with symmetric and asymmetric opening, were further developed in the computational model. In order to simplify the results and overcome the issue of record-to-record variability, simple sinusoidal acceleration waveforms were applied to the walls with varying frequency and acceleration amplitudes. The results showed that the overall wall displacement is not consistent in providing damage accumulation. If, even after much accumulation of damage and collection of residual damage, a convenient earthquake motion is applied, the accumulated residuals can go back to zero or to the opposite direction with a different amplitude. This naturally does not mean that the cracks were diminished. In other words, monitoring only the structural lateral deformations and residuals is not enough to quantify the accumulation of damage. An approach that accounts for the position, width and distribution of cracks is needed. Joint slip (sliding of a joint over others, as happens in the case of bed joint shear failure), as well as joint opening, were monitored in the discrete element wall models. Joint slip and joint opening values for the solid wall were not meaningfully large and thus not reported here. But the results of the walls with asymmetric and symmetric openings were presented and discussed. A measure for quantifying the residual damage after each loading is the ratio of the total maximum joint slip (crack) length to the total residual joint slip length.

Joint opening is a metric that is expected to be sensitive to rocking, that is the case of walls with openings. This is because the slender piers on the sides of the opening rock and develop cracks, that can be detected by measuring the joint opening. Once the rocking-related cracks develop, the total crack length does not increase significantly when the acceleration amplitude increases. This finding suggests that the joint slip and joint opening are two distinct metrics that need to be monitored individually since they are related to different damage mechanisms.

Detailed modelling approaches for URM, such as discrete-element modelling, micromodelling or applied element methods, use block approach for the units and interface elements for the mortar joints. The interfaces are formulated with springs or spring-like connections. It is concluded in this paper that, if damage accumulation is to be accurately captured in such models, the constitutive laws applied to the nodal spring or spring-like connections should involve some sort of degradation of strength and/or stiffness. Detailed experimental data would obviously be needed to account for the phenomenon in the interaction model used for the joints.

Another observation is that the accumulation of damage, both in detailed and in complicated models, is quite sensitive to the frequency content of the applied motion, something expected for any structural system in terms of the overall seismic response. However, it was 
found that even the cracks distribution, i.e. slip and opening of joints, is more responsive to the frequency of the motion than the amplitude of it. In other words, an induced earthquake motion with lower amplitude, provided that possesses the appropriate frequency content, could cause higher number and intensity of cracks to the URM walls, at least to those similar to the walls examined here.

Acknowledgements The authors would like to thank Rui Pinho for providing the analyses data of the reports from Mozayk. Francesco Graziotti is also acknowledged for providing experimental data and facilitating the authors in the correct interpretation of these data.

\section{References}

Arias A (1970) A measure of earthquake intensity. In: Hansen RJ (ed) Seismic design for nuclear power plants. MIT Press, Cambridge, pp 438-483

Aschheim M, Black E (1999) Effects of prior earthquake damage on response of simple stiffness-degrading structures. Earthq Spectra 15(1):1-24

Chai YH (2005) Incorporating low-cycle fatigue model into duration-dependent inelastic design spectra. Earthq Eng Struct Dyn 34:83-96. https://doi.org/10.1002/eqe.422

Crowley H, Pinho R (2017) Report on the v5 fragility and consequence models for the Groningen Field, Pavia. A report prepared for NAM (Nederlandse Aardolie Maatschappij). https://nam-feitenencijfers .data-app.n1/download/rapportdialog/aaa228dc-71a3-4919-a560-571a4b262a9a. Accessed 11 Nov 2018

Dais D, Bal İE, Smyrou E (2017) Discussion on the response of unreinforced masonry to low-amplitude recursive loads: case of groningen gas field. In: Proceedings of COMPDYN 2017, Rhodes, Greece

Di Sarno L (2013) Effects of multiple earthquakes on inelastic structural response. Eng Struct 56:673-681. https://doi.org/10.1016/j.engstruct.2013.05.041

Elnashai AS, Di Sarno L (2008) Fundamentals of earthquake engineering. Wiley, London

Esposito R, Terwel KC, Ravenshorst GJP, Schipper HR, Messali F, Rots JG (2017) Cyclic pushover test on an unreinforced masonry structure resembling a typical Dutch terraced house. In: Proceedings of the 16th world conference earthquake, Santiago, Chile

Giardina G (2013) Modelling of settlement induced building damage. Ph.D. thesis, TU Delft, The Netherlands

Graziotti F, Tomassetti U, Rossi A, Kallioras S, Mandirola M, Cenja E, Penna A, Magenes G (2015) Experimental campaign on cavity-wall systems representative of the Groningen building stock. Report, EUC318/2015U, EUCENTRE, Pavia, Italy

Graziotti F, Rossi A, Mandirola M, Penna A, Magenes G (2016) Experimental characterisation of calciumsilicate brick masonry for seismic assessment. In: Brick and block masonry: trends, innovations and challenges - proceedings of the 16th international brick and block masonry conference, IBMAC 2016, pp 1619-1628

Graziotti F, Tomassetti U, Kallioras S, Penna A, Magenes G (2017) Shaking table test on a full scale URM cavity wall building. Bull Earthq Eng 15(12):5329-5364

Graziotti F, Penna A, Magenes G (2018) Shaking table test on a full scale URM cavity wall building. Bull Earthq Eng. https://doi.org/10.1007/s10518-018-0478-6

Hatzigeorgiou GD, Beskos DE (2009) Inelastic displacement ratios for SDOF structures subjected to repeated earthquakes. Eng Struct 31(11):2744-2755

Iervolino I, Giorgio M, Chioccarelli E (2013) Gamma degradation models for earthquake-resistant structures. Struct Saf 45:48-58. https://doi.org/10.1016/j.strusafe.2013.09.001

ITASCA (2011) UDEC - universal distinct element code manual: theory and background. Itasca Consulting Group, Minneapolis

Kohrangi M, Bazzurro P, Vamvatsikos D, Andrea Spillatura A (2017) Conditional spectrum-based ground motion record selection using average spectral acceleration. Earthq Eng Struct Dyn 46(10):1667-1685

Korswagen PA, Meulman E, Longo M, Rots JG (2018) Light crack initiation and propagation in unreinforced masonry specimens subjected to repeated loading such as earthquake vibrations. In: Milani G, Taliercio A, Garrity S (eds) 10th International masonry conference, Milan, Italy, 9-11 July 2018 
Max D, Abbiati G, Broccardo M, Beyer K, Danciu L, Petrović M, Mojsilović N, Stojadinovic B (2017) Quantification of non-structural damage in unreinforced masonry walls induced by geothermal reservoir exploration using quasi-static cyclic tests. In: Proceedings of the 13th Canadian masonry symposium, Halifax, Canada

McKenna F, Fenves GL, Scott MH (2000) Open system for earthquake engineering simulation. University of California, Berkeley

Meguro K, Tagel-Din H (2000) Applied element method for structural analysis: theory and application for linear materials. JSCE Int J Struct Eng Earthq Eng 17(1):21-35

Mouyiannou A, Penna A, Rota M, Graziotti F, Magenes G (2014) Implications of cumulated seismic damage on the seismic performance of unreinforced masonry buildings. Bull N Z Soc Earthq Eng 47(2):157-170

Mozayk (2017) Nonlinear dynamic analysis of index buildings for v5 fragility and consequence models. Deliverable D8. A report prepared for NAM (Nederlandse Aardolie Maatschappij) by Pinho R, Malomo D, and Brunesi E and reviewed by Helen Crowley. https://nam-feitenencijfers.data-app.nl/ download/rapport/f479bb9c-807c-4c08-8aaf-17e10c278f20?open=true. Accessed 11 Nov 2018

Rots JG, Messali F, Esposito R, Mariani V, Jafari S (2017) Multi-scale approach towards groningen masonry and induced seismicity. Key Eng Mater 747:653-661

Sarhosis V, Sheng Y (2014) Identification of material parameters for low bond strength masonry. Eng Struct 60:100-110

Sarhosis V, Oliveira DV, Lemos JV, Lourenco PB (2014) The effect of skew angle on the mechanical behaviour of masonry arches. Mech Res Commun 61:53-59

Sarhosis V, Garrity SW, Sheng Y (2015) Influence of brick-mortar interface on the mechanical behaviour of low bond strength masonry brickwork lintels. Eng Struct 88:1-11

Schijve J (2009) Fatigue of structures and materials. Springer, Berlin

Takeda T, Sozen MA, Nielsen NN (1970) Reinforced concrete response to simulated earthquake. ASCE J Struct Div 96(ST12):2557-2573

Tomassetti U, Correia AA, Graziotti F, Marques AI, Mandirola M, Candeias PX (2017) Collapse shaking table test on URM cavity wall building representative of a Dutch terraced house. European Centre of Training and Research in Earthquake Engineering (EUCENTRE), Pavia. A report prepared for NAM (Nederlandse Aardolie Maatschappij)

Tomor A, De Santis S, Wang J (2013) Fatigue deterioration process of brick masonry. Mason Int 26(2):41-48

van Elk J, Doornhof D (2017) Induced seismicity in Groningen-assessment of hazard, building damage and risk, report prepared for NAM (Nederlandse Aardolie Maatschappij). https://nam-feitenencijfers .data-app.nl/download/rapportdialog/3bebaa86-70cd-4d72-bf22-2346796d69ac. Accessed 11 Nov 2018

Vasconcelos G, Lourenço PB (2009) Experimental characterization of stone masonry in shear and compression. Constr Build Mater 23:3337-3345. https://doi.org/10.1016/j.conbuildmat.2009.06.045

Zucchini A, Lourenço PB (2009) A micro-mechanical homogenisation model for masonry: application to shear walls. Int J Solids Struct 46:871-886. https://doi.org/10.1016/j.ijsolstr.2008.09.034

Publisher's Note Springer Nature remains neutral with regard to jurisdictional claims in published maps and institutional affiliations. 